\section{H Bhattarai}

Ganesh Man Singh Memorial

Academy of ENT and head and Neck

Studies, TU Teaching Hospital,

Kathmandu, Nepal

\section{Correspondence to}

Dr. Hari Bhattarai,

GPO Box No.6559

Email:sukhaura@gmail.com

\section{Benign Paroxysmal Positional Vertigo: Present Perspective} history of benign paroxysmal positional vertigo (BPPV), various diagnostic and therapeutic procedures in use for its different variants and rate of its recurrence after treatment. Representative articles were selected and reviewed. Idiopathic canalolithiasis of posterior semicircular canal is the commonest pathology. Making correct diagnosis of different clinical variants is at times challenging. Once diagnosed most of these conditions respond well to simple office based particle repositioning maneuvers (PRM). BPPV can spontaneously abate in some cases. Recurrence with secondary types of BPPV is more than with that of idiopathic variety. Awareness and recognition of this condition is very important as vertigo is often treated by different specialties in Nepal.

Keywords:

BPPV, Benign Paroxysmal Positional Vertigo, Dix-Hallpike procedure and Epley maneuver.

\section{INTRODUCTION:}

Temporal bone dissection findings dramatically have changed the perception of BPPV). 1 The clinical presentation of this common condition is straightforward but the choice of diagnostic and therapeutic maneuvers at times can be challenging. 2 Although termed benign, it can be a severe and disabling problem for some of the patients. It affects the quality of life of its sufferers and can be associated with reduced activities of daily life, falls, and depression especially in geriatric patients. 3 Barany, in 1921, first described BPPV as episodic vertigo of acute onset and oflimited duration induced by change in head position in relation to gravity. 4 In 1952, otologists Dix and Hallpike described a provocative maneuver to induce positional nystagmus in patients with BPPV. Their work determined the cardinal manifestations of BPPV and helped in the lateralization of the affected ear, and its characterization as central and peripheral. In 1969, Schuknecht proposed the 'heavy cupula theory' (cupulolithiasis). Cupulolithiasis theory could explain the linear rotatory nystagmus, its latency and recurrence of nystagmus and vertigo after rest. However, it could not explain the mechanism of brief duration of the nystagmusand reversal of the nystagmus with the return to a sitting position. 5 In 1979, Hall et al put forward their view on the mechanism of stimulation of the posterior semicircular canal (PSC) by free-floating particles rather than heavy cupula. This concept was later termed the 'theory of canalithiasis'by Epley. ${ }^{5}$ This theory could explain unanswered questions of cupulolithiasis theory. This led to the evolvement of safe canalolith repositioning procedures (CRP), described by Epley in 1980 and Semont et al in 1998. This theory also led to development of a surgical approach of occlusion of PSC as described by Parnes and McClure in 1990. In 1985, McClure reported on several patients with a clinical picture was suggestive of horizontal semicircular canal (HSC) involvement. Anterior semicircular canal (ASC) variant was described by Steddin and Brandt in $1994 .^{1}$

\section{Incidence}

Froehling et al 6 have suggested an incidence of 64 cases of BPPV per100,000 residents. Lifetime prevalence of this condition is estimated to be $3.2 \%$ in females, $1.6 \%$ in males, and $2.4 \%$ overall. ${ }^{1}$ About 20 percent of all dizziness is due to BPPV and it accounts for approximately $24 \%$ of all cases of peripheral vestibular disorders. 7 Incidence of BPPV increases with each decade and reaches the peak at the sixth to seventh decade of life. 6 Women are more affected than men, with a 2:1 ratio. 8 Right side is affected more than the left. This may be due to a subjective preference amongst patients for a right head-lying position during sleep. 8 The posterior semicircular canal BPPV (PC-
BPPV) is seen in most of the cases,likely because the opening and positioning of the posterior canal is in a gravity-dependent position. BPPV may also affect the other semicircular canals (SCC) but with lower prevalence. ${ }^{9}$ Horizontal semicircular canal (HC-BPPV) accounts for approximately $10 \%$ to $20 \%$ of all patients presenting with BPPV. 10 Anterior canal BPPV (AC-BPPV) is still considered to be a rare variant, and accounting for about $2 \%$ of cases. 11 Usually, debris within the anterior SCC is self-cleared, because its posterior arm descends directly into the common crus and the utricle.1 Bilateral BPPV is rather rare, accounting for $6 \%$ to $26 \%$ in the reported BPPV series. 8

\section{Etiology}

BPPV in most cases, about $50 \%$, is considered to be idiopathic. 9 Various predisposing factors that damage and dislodge otoconia have been associated with the development of BPPV. Sudden acceleration or deceleration of head trauma creates ruptures in segments of the macula and is more likely to be associated AC-BPPV. ${ }^{1}$ In dental implant surgery vibration of dental turbine and forced head positioning induce loosening of otoconia.In cochlear implantation the fall of bone dust particles into the cochlea during the cochleostomy, the vibration caused while boring the cochlea and electric stimulation are sufficient to dislodge the otoconia.12 Labyrinthitis may also cause BPPV by inflammatory effects within or near the macula or by compromise of its vascular supply. ${ }^{9}$ The likelihood of developing BPPV may relate, in part, to metabolic considerations and the elastic and adhesive properties of the gelatinous otoconia within the maculae. ${ }^{9}$ In migraine, spasm of the labyrinthine arteries induce local ischemia facilitating otoconial detachment.13 It has been proposed that endolymphatichydrops damages the utricle resulting in loose otoconia. Vestibular neuronitis may simultaneously damage the utricle and detach the otoconia and bring upon BPPV. ${ }^{14}$ Labyrinthine infarction because of blockage of anterior vestibular artery that provides the vascular supply to the ASC, HSC and utricle can also lead to BPPV. 9 Vigorous exercises as jogging, treadmill exercise and marathon running can cause BPPV. These conditions seem to lead mostly to PC-BPPV. 15 A temporal bone study in humans without vestibular disease showed a substantial decrease of otoconia in elderly persons compared with children. This finding raises the question as to whether all humans lose otoconia with advancing age and are thus prone to develop BPPV. 16 Prolonged bed rest, other ear disorders and ear surgeries are also suspected to be etiological factors. 17 Finally a positive family history has been described in some patients with BPPV.16 
Pathophysiology

The concepts of cupulolithiasis and canalolithiasis have been the working hypotheses of BPPV for the last 30 years; both medical and surgical therapies target this site, with huge success. ${ }^{1}$ Cupulolithiasmaintains that otolithic debris normally found in the utricle and saccule becomes displaced to the cupula of the PSCC. This then renders the organ gravity sensitive. 18 Thecanalilithiasis, the most common hypothesis, proposes that otolithic debris float freely between the ampulla and common crus of the PSCC (Fig- 1). 18 It has been suggested that the size or mass of the debris within the SCC needs to reach a critical level before BPPV symptoms develop.19 Prolonged head-lying on one side seems to favour the entrance of more otoliths into SSC of the lowermost ear. Anatomical differences in the orientation of the SCC may facilitate or hinder the entrance of otoconia (Fig- 2). 20

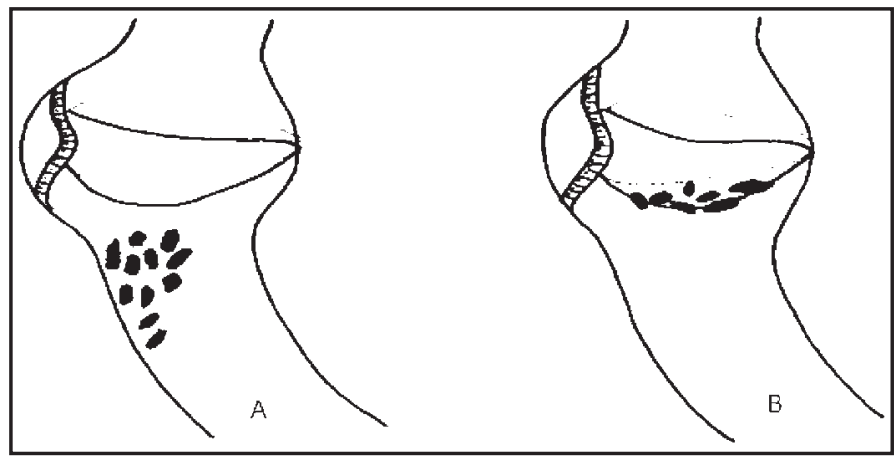

Fig: 1. A, Canalilithiasis; B, Cupulolithiasis. ${ }^{9}$

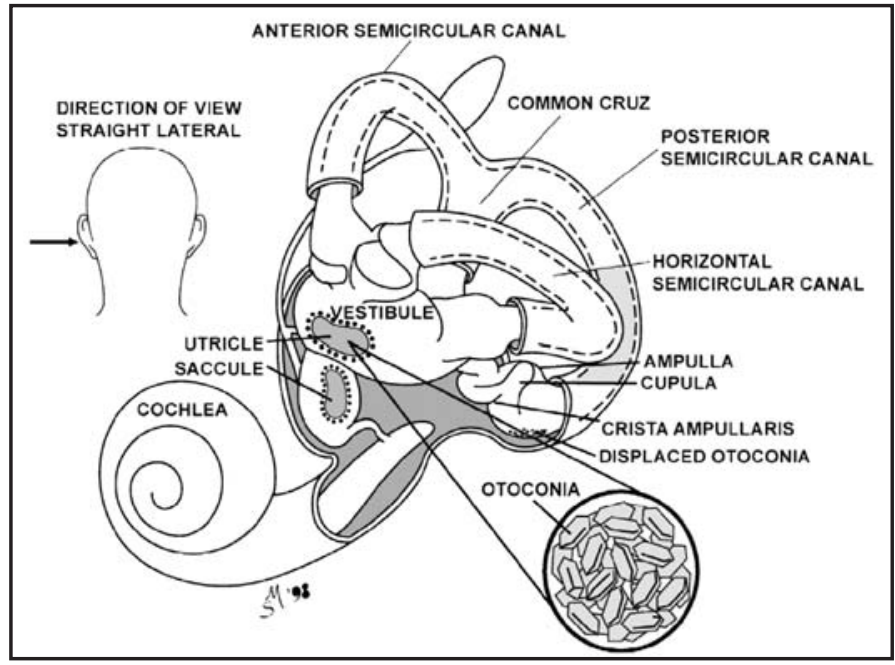

Fig: 2. Mechanism of BPPV. 9

Occasionally, freely mobile otoconia moving within the lumen of one SSC can inadvertently move to one of the adjacent canals during the course of treatment rather than to the utricle as intended. This canal switch changes the appearance of nystagmus from that of the originally affected canal to that of the newly affected.21 The most common canal switches are from PSC to the HSC and PSC to ASC. 9

In recent years, two types of HC-BPPV have been recognized. One with geotropic and the other with apogeotropic positional nystagmusseen during diagnostic maneuvers. ${ }^{22}$ The pathophysiology of the former is thought to be canalolithiasis and that of latter is still controversial, with cupulolithiasis in the HSCC being reported as the most plausible cause. 22 Two forms of cupulolithiasis, characterized by otoliths attached either on the utricle-side or the canal-side cupula, have been also identified.23 AC- BPPV is usually transitory and most often seen in the course of treating other more common forms of BPPV. 9

In some situations more than one canal is affected at the same time. The most common circumstance is probably bilateral posterior canal BPPV. ${ }^{9}$ Combined HSC and PSC form of BPPV is seen especially in cases of head trauma. ${ }^{24}$ Even after successful repositioning free- floating canaliths would be expected to re-accumulate within the PSC over time resulting in recurrent symptoms. ${ }^{25}$ BPPV has a recurrence rate of approximately $15 \%$ per year. 20 It appears that post-traumatic BPPV has a greater tendency to recur. Of PC-BPPV successfully treated with the CRP, 44\% redevelop BPPV within the first 2 years. 26 Sleep seems to be involved in the pathophysiology of BPPV. 27 Fixed positioningof the head during sleep may facilitate the deposition of particles on the cupula or in the PSCC. 28

BPPV can spontaneously abate in some cases, but this typically occurs within the first month of onset. Asawavichianginda et alalso showed after 3 months, $84 \%$ of patients with PC-BPPV who received no treatment had converted to a negative Hallpike maneuver. 29 It can be explained by the orientations of the canals that the spontaneous remission of HC-BPPV was shorter than that of PC-BPPV. Any debris entering the PSC that hangs inferiorly from common crus essentially becomes trapped within. In contrast, HSC slopes slightly up and has its cupula at the upper end. Therefore, free-floating debris in the HSC would tend to float back out into the utricle as a result of natural head movements. 30 Geotropic HC-BPPV disappeared naturally within about 2 weeks without physiotherapy. 31

\section{Clinical presentation}

Vertigo with nausea and vomiting is the most common symptom that occurs with change of head positionespecially while looking up, getting out of bed, rolling over in bed, bending, looking up (top-shelf syndrome) and with quick head movements. 8 Majority of patients in one study reported that their BPPV started while turning in bed during the night or while rising from bed in the morning (morning dizziness). 32 Patients do not always demonstrate the typical complaint of vertigo. It has been reported that some individuals complain of lightheadedness, dizziness or the feeling of being off-balance rather than the typical definition of true vertigo. BPPV may manifest as falls in older individuals so early diagnosis is necessary and dizziness handicap inventory ( $\mathrm{DHI}$ ) may be predictive in some cases. 32 BPPV of HSC gives rise to symptoms of episodes of vertigo that usually wakes the patient up during the night, is of a high intensity, and takes a long time to recede spontaneously, forcing the patient to remain almost immobile. 33 Side-to-side rolling in bed that causes vertigo in both directions suggests HC- BPPV but can also occur in patients who have bilateral PC-BPPV.

\section{Diagnostic Tests}

Differentiation between canalilithiasis and cupulolithiasis and the canal affected can be done with the help various diagnostic tests. Before we embark upon these tests the patient should be warned that this will provoke their dizziness but that they should remain in this position until such symptoms subside. 34

Diagnosis of unilateral PC- BPPV due to canalithiasis, is based on the presence of an upbeating and torsional nystagmus elicited in the Hallpike-Dix position with concurrent experience of vertigo. The nystagmus has a latency of onset of 2 to 20 seconds, lasts $<60$ seconds, and reverses when the patient returns to the sitting position. The torsional component of the nystagmus beats towards the affected and lowermost ear while a vertical upbeating component is superimposed. 35 In bilateral PC-BPPV it is hard to decide which side is more symptomatic. 36

It is not always easy to demonstrate observable nystagmus that is typical of BPPV and so it may be necessary to examine the patient more than once. Nunezet al have suggested that the Dix-Hallpike test can be affected by the speed of the maneuver and the plane of the occiput and that it may vary from day to day. It will be difficult to perform Dix-Hallpike procedure in obese or frail individuals, patients with stroke, anxiety states and neck trauma. 32 For such individuals various other diagnostic maneuvres have been suggested like Li Maneuvre based on subjective vertigo but not on nystagmus. ${ }^{37}$ andside-lying maneuver. ${ }^{9}$

HC-BPPV is often, but not always, evoked by Dix-Hallpike maneuver. The nystagmus of HC-BPPV is distinctly horizontal and changes direction with changes in head position. The best way to diagnose HC-BPPV is by a supine head turn maneuver (Pagnini-McClure maneuver), in which the patient in the supine face-up position turns his or her head quickly to the right and left. Geotropic direction 
changing positional nystagmus is right beating upon turning the head to the right and then left beating when turning the head back to the left side. Conversely, ageotropic indicates the nystagmus is right beating with turning to the left and left beating with turning to the right. The other alternative tests for the diagnosis of horizontal canal BPPV are bow and lean test 38 and Li maneuver. 37

The Dix-Hallpike and side-lying tests used for the posterior canal BPPV can also be used to provoke and diagnose anterior canal BPPV. ${ }^{9}$ During Dix-Hallpikemaneuver if patient has anterior AC-BPPV, the headhanging position generates a burst of downbeating nystagmus. ${ }^{26}$ The direction of subtle vertical-beating nystagmus underlying the torsional component is critical in differentiating $A C$ versus $P C$ origin Electro-oculography/videooculography aid in accurate assessment of the vertical component for the diagnosis of canal involvement. Patients with a history of head trauma should be examined closely for AC involvement. 39

In some situations more than one canal is affected at the same time.The most common circumstance is probably bilateral posterior canal BPPV. This can be diagnosed by the presence of typical nystagmus with DixHallpike or sidelying maneuvers on both the right and left sides. Combinations of posterior and horizontal canal variants can be recognized based on the maneuver used to evoke the nystagmus and the direction of the nystagmus. ${ }^{5}$

\section{Treatment}

For many years, treatment of BPPV involved exercises to induce habituation and compensation.Medical treatment in the form of antivertiginousdrugs has been generally found to be ineffective. 39 Recent controlled studies have clearly established that physical maneuvers based on inner ear biomechanics are highly effective for PC-BPPV. In these maneuvers, the head is positioned such that loose otoconia are allowed to sediment back within the labyrinth. 41

Appearance of a nystagmus is probably related to the amount of cupula or canal otoconia particles and might well reflect an advanced or acute stage of the disorder. Therefore, for the purpose of treatment of BPPV by repositioning maneuvers, it is not essential to observe a positional and positioning nystagmus; symptoms of vertigo connected to positional and positioning tests are sufficient. 42

Two office procedures are very effective for PC-BPPV. Canalith repositioning treatment (CRT) (synonyms: canalith repositioning maneuver, particle repositioning procedure or maneuver, Epley maneuver or procedure, modified Epley maneuver) is the most commonly used method for treatment of posterior canal BPPV, at least in the United States. The second treatment technique is the Semontliberatory maneuver (synonyms: liberatory maneuver or treatment,Semont maneuver or treatment) more often in Europe. 9 In CRT $5^{\text {th }}$ patient is moved through a series of 4 positions. With each position,the otoconia moves toward the lowest part of the canal, resulting in the movement of the otoconia around the arc of the long arm of the PC into the common crus and depositing the otoconia into the insensitive vestibule. ${ }^{26}$ Although some advocate the use of mastoid vibrator,5or head shaking in each position, 42 these appear to make little difference, at least in most patients with BPPV. 9

Epley maneuver may be difficult in patients with problems of cervical spine like spondylosis, disc prolapse, previous cervical spine fracture and cervical spine rheumatoid arthritis. Modified Epley with neck collar performed in an adjustable operating table is suggested. 46 Those patients who do not benefit from initial CRP may be advised self CRP at home and it is found not to affect the time to recurrence and the rate of recurrence of posterior canal. 26

Epley recommended some posture restrictions such as sleeping in a seated position or with 45 -degree elevation for 48 hours. 47 Since then several modifications of the original repositioning maneuver and postprocedure instructions have been recommended in order to prevent otoconia from moving back into the semicircular canals. Patients are advised to avoid symptom-provoking positions, to wear a soft cervical collar,to sleep at a 45-degree angle for 2 nights and to avoid lying on the involved side, refrain from rapid head movements, 26 turning to the affected side, and flexing or extending their neck for 48 hours. 5 In the last few years, several articles have evaluated the convenience of postural restrictions. 47 However, based on current evidence; the use of postural restrictions after the canal-repositioning maneuver is unjustified. 5

The Semont maneuver may be difficult to perform in some older or obese people because of the quick sweeping movement from one side to the other. It may be used for BPPV of the posterior canal caused by canalithiasis or for refractory cases presumed to be due to cupulolithiasis.9

The other procedures for PC BPPV are Brant-Darroffredistribution exercises. 32 Parnes' particlerepositioning maneuver (PRM) 47 and various modifications of Epley.However, thereis a significant number of patients who either do not respond to therapy and require repeated maneuvers in multiple sessions or who responded initially but develope rapid recurrence of their symptoms. 48 Perhaps, the most common reason for failure in these patients with an accurate diagnosis is insufficient extension of the head. If the head is not at least somewhat tilted back, the otoconia particles will not move through the canal properly. Severe kyphosis can make the positioning of the head difficult. 9

Several repositioning maneuvers such as the Semont maneuver 49 Lempert's maneuver(360 degree barbecue rotation) and forced prolonged position (FPP, or Vannucchimanoeuvre)48 Gufoni maneuver 50 have been used for the treatment of HC-BPPV. FPP, which requires patients to lie on the healthy side for 12 hours, is regarded as the most natural and comfortable treatment.

However, the success rate of HSC-BPPV is approximately $60 \%$ to $90 \%$; this value is significantly lower than those of PSC-BPPV. As the ASC follows adifferent trajectory from the posterior canal, maneuvers to treat AC-BPPV must necessarily differ geometrically from those described by Epley and Semont for PC-BPPV. AC-BPPV can be treated with the same maneuvers used to treat PC-BPPV but it may be difficult to ascertain the affected side unless it developed from canal switch. It is probably advisable to repeat Dix-Hallpike positioning on both sides to be sure no persisting nystagmus or symptoms are present. 51

In this regard, there have been several non-controlled studies concerning the treatment of anterior canal BPPV. Honrubia et al52 mention a "Reverse Epley" postural repositioning procedure. The "Reverse Semont" maneuver has also beenrecommended-as head positions with respect to gravity are identical to those of the Epley maneuver, this procedure is likely to be equally effective. Another maneuver for AC-BPPV was described by Rahko. 53 Crevits 54 described a "Prolonged Forced Position procedure'.Helminski and Hain55 proposedusing a "deep Dix-Hallpike" maneuver for AC-BPPV. Others treatment alternatives, so far without scientific studies proving efficacy, include the Brandt Daroff exercise and the reverse Semont maneuver. ${ }^{1}$

If one has simultaneous PSC and HSC BPPVthe patient should be managed by first using the PSCmaneuver and then, three days later, the HSC manoeuvre. ${ }^{37}$ Epley defined resolution of BPPV as "a negative Hallpike maneuver on follow-up exam and no further positional vertigo for one month following the last treatment."5 Although three years' absence of symptoms is generally considered as a definitive cure. 48

Recurrence

For PC-BPPV, Marciano and Marcelli56 and Moon et al 57 have reported recurrence rates approximately $10 \%$ during a short-term follow-up, and Cakir et al58 have reported even higher rates (20\%) during a longterm follow-up. Despite the successful application of appropriate CRT at present, it is still controversial which factors are associated with treatment failure. Elderly patients responded less well to initial CRP treatment. This may have been due to poor cooperation, fatigue or limited mobility. Furthermore, disease may be more extensive in older patients and otoconial debris may be produced more frequently and in larger quantities than in younger patients. Patients with a history of head and neck trauma associated with the disease responded poorly to CRP treatment, with a cure rate of only 36 per cent after two treatments. Most reports generally agree that secondary BPPV has a worse prognosis than idiopathic BPPV.59,60 It has been reported that in patients with abnormal ENG findings outcome are worse on both initial and repeat treatment. This may be explained by more extensive damage of the labyrinth in such cases. 42 Macias et al62 found that BPPV involving any location other than a single PSC required more 
than one treatment visit. Furthermore, they found that HC-BPPV responded less to therapy than did PC-BPPV. One of the causes for this low success rate is the difficulty in identifying the affected side because of recently recognized variantsof HSC-BPPV. 2 The otolith causing HC-BPPV may be adherent to the cupula or less mobile. The otolith may not be able to leave the canal because it is too big for the HSC lumen or the exit of the HSC into theutricle. We can occasionally see that the barbecue rotation causes a change from canalolithiasis to the cupulolithiasis type in several patients. 45 In addition, incorrect canalith repositioning maneuvers such as insufficient head rotation and time and failure to maintain $30^{\circ}$ head flexion may be contributing causes. 43

\section{Surgery}

Surgery is reserved for severe and persistent cases in which CRT is unsuccessful. Earlier destructive procedures were performed aiming at the whole labyrinth, by alcohol injection (labyrintholysis) or labyrinthectomy 1 but recently conservative surgery like posterior semicircular canal occlusion and ampullary nervesection 40 vestibular nerve section, microvascular decompression of the eighth cranial nerve5are performend. Laser occlusion of PSC for BPPV is also described. 45 For AC- BPPV plugging of the AC has been applied. 44

\section{CONCLUSION:}

New variants of BPPV are being recognized; new, effective and simpler diagnostic tests and therapeutic maneuvers are being developed for each variant of BPPV. Management of BPPV has been moving, in part away from treatment by health care professionals in the office and back into the home via self-treatment with either a modified Epley procedure or a modified Semont maneuver. The use of a multi axial positioning device applicable to all variants and in difficult BPPV patients shall be the subject of future publications.

\section{REFERENCES:}

1 Marom T, Oron Y, Watad W, Levy D, Roth Y. Revisiting benign paroxysmal positional vertigo pathophysiology. Am J Otolaryngol 2009; 30: 250-5.

2. Choung YH, Shin YR, Kahng H, Park K, Choi SJ. 'Bow and lean test' to determine the affected ear of horizontal canal benign Paroxysmal positional vertigo. Laryngoscope 2006; 116: 1776-81.

3. Oghalai JS, Manolidis S, Barth JL, Stewart MG, Jenkins HA. Unrecognized benign paroxysmal positional vertigo in elderly patients. Otolaryngol Head Neck Surg 2000; 122: 630-4

4. Steenerson RL, Cronin GW, Marbach PM. Effectiveness of treatment techniques in 923 Cases of benign paroxysmal positional vertigo. Laryngoscope 2005; 115: 226-31.

5. Mohammad M, Najam-ul-Hasnain K. Epley's manoeuvre: treatment of choice for benign paroxysmal positional vertigo. J Laryngol Otol 2000; 114: 844-7.

6. Froehling DA, Silverstein MD, Mohr DN, Beatty CW, Offord KP Ballard DJ. Benign positional vertigo: incidence and prognosis in a population-based study in Olmsted County, Minnesota. Mayo Clin Proc 1991; 66: 596-601.

7. Asprella Libonati G, Gagliardi G, Cifarelli D, Larotonda G. "Step by step" treatment of lateral semicircular canal canalolithiasis under videonystagmoscopic examination. Acta Otorhinolaryngol Ital 2003; 23: 10-5.

8. Baloh RW, Honrubia V, Jacobson K. Benign positional vertigo: clinical and oculographic features in 240 cases. Neurology 1987; 37: 371-8.

9. Fife TD. Recurrent positional vertigo. Continuum: Lifelong learning in Neurology 2006; 12: 92-115.

10. Baloh RW, Yue Q, Jacobson KM, Honrubia V. Persistent directionchanging positional nystagmus: another variant of benign positional nystagmus? Neurology 1995; 45: 1297-1301.

11. Jackson LE, Morgan B, Fletcher JC Jr, Krueger WW. Anterior canal benign paroxysmal positional vertigo: an underappreciated entity. Otol Neurotol 2007; 28: 218-22.

12. Viccaro M, Mancini P, La Gamma R, De Seta E, Covelli E, Filipo R Positional vertigo and cochlear implantation. Otol Neurotol 2007; 28: 764-7.

13. Ishiyama A, Jacobson KM, Baloh RW. Migraine and benign positional vertigo. Ann Otol Rhinol Laryngol 2000; 109: 377-80.

14. Karlberg M, Hall K, Quickert N, Hinson J, Halmagyi GM. What inner ear diseases cause benign paroxysmal positional vertigo? Acta Otolaryngol 2000; 120: 380-5.

15. Gordon CR, Levite R, Joffe V, Gadoth N. Is posttraumatic benign paroxysmal positional vertigo different from the idiopathic form? Arch Neurol 2004; 61: 1590-3.

16. von Brevern M, Schmdt T, Schönfeld $U$, Lempert T, Clarke AH. Utricular Dysfunction in Patients with Benign Paroxysmal Positional Vertigo. Otol Neurotol 2006 27: 92-6.

17. Cakir BO, Ercan I, Cakir ZA, Civelek S, Turgut S. Relationship between the affected ear in benign paroxysmal positional vertigo and habitual head-lying side during bed rest. J Laryngol Otol 2006; 120: $534-6$

18. Woodworth BA, Gillespie MB, Lambert PR. The canalith repositioning procedure for benign positional vertigo: a metaanalysis. Laryngoscope 2004; 114: 1143-6.

19. Hall SF, Ruby RRF, McClure JA. The mechanics of benign paroxysmal positional vertigo. J Otolaryngol 1979; 8: 151-8.

20. Korres SG, Papadakis CE, Riga MG, Balatsouras DG , Dikeos DG, Soldatos CR. Sleep position and laterality of benign paroxysmal positional vertigo. J Laryngol Otol 2008; 122: 1295-8.

21. Parnes LS, McClure JA. Free-floating endolymph particles: a new operative finding during posterior semicircular canal occlusion. Laryngoscope 1992; 102: 988-92.

22. Bisdorff AR, Debatisse D. Localizing signs in positional vertigo due to lateral canal cupulolithiasis. Neurology 2001; 57: 1085-8.

23. Herdman SJ, Tusa RJ, Zee DS, Mattox DE. Single treatment approaches to benign paroxysmal positional vertigo. Arch Otolaryngol Head Neck Surg 1993; 119: 450-4.

24. Bertholon P, Chelikh L, Tringali S, Timoshenko A, Martin C. Combined horizontal and posterior canal benign paroxysmal positional vertigo in three patients with head trauma. Ann Otol Rhinol Laryngol 2005; 114: 105-10.

25. Banfield GK, Wood C, Knight J. Does vestibular habituation still have a place in the treatment of benign paroxysmal positional vertigo? J Laryngol Otol 2000; 114: 501-5.

26. Helminski JO, Janssen I, Hain TC. Daily Exercise Does Not Prevent Recurrence of Benign Paroxysmal Positional Vertigo. Otol Neurotol 2008; 29: 976-81.

27. Giacomini PG, Ferraro S, Di Girolamo S, Villanova I, Ottaviani F. Benign paroxysmal positional vertigo after intense physical activity: a report of nine cases. Eur Arch Otorhinolaryngol 2009; 266: 18315.

28. Lopez-Escámez JA, Gámiz MJ, Fi?ana MG, Perez AF, Canet IS. Position in bed is associated with left or right location in benign paroxysmal positional vertigo of the posterior semicircular canal. Am J Otolaryngol 2002; 23: 263-6

29. Asawavichianginda S, Isipradit $P$, Snidvongs K, Supiyaphun P. Canalith positioning for benign paroxysmal positional vertigo: a randomized, controlled trial. Ear Nose Throat J 2000; 79: 732- 4.

30. Kazunori S, Takao I, Go S, Mahito I, Noriaki T. Natural history of benign paroxysmal positional vertigo and efficacy of Epley and Lempert maneuvers. Otolaryngology Head Neck Surg 2006; 135: 529-33

31. Imai T, Ito $M$, Takeda $N$, Uno A, Matsunaga T, Sekine $K$, et al. Natural course of the remission of vertigo in patients with benign paroxysmal positional vertigo. Neurology 2005; 64: 920-1.

32. Whitney SL, Marchetti GF, Morris LO. Usefulness of the dizziness handicap inventory in the screening for benign paroxysmal positional vertigo. Otol Neurotol 2005; 26: 1027-33.

33. Epley JM. New dimensions of benign paroxysmal positional vertigo. Otolaryngol Head Neck Surg 1990; 88: 599-605.

34. Banfield GK, Wood C, Knight J. Does vestibular habituation still have a place in the treatment of benign paroxysmal positional vertigo? J Laryngol Otol 2000; 114: 501-5.

35. Roberts RA, Gans RE, Kastner AH. Differentiation of migrainous positional vertigo (MPV) from horizontal canal benign paroxysmal positional vertigo (HC-BPPV). Int J Audiol 2006; 45: 224-6.

36. Pollak L, Stryjer R, Kushnir M, Flechter S. Approach to bilateral benign paroxysmal positioning vertigo. Am J Otolaryngol 2006; 27: $91-5$

$37 \mathrm{LI} \mathrm{J,} \mathrm{LI} \mathrm{H.} \mathrm{New} \mathrm{repositioning} \mathrm{techniques} \mathrm{for} \mathrm{benign} \mathrm{paroxysmal}$ positional vertigo: the Li repositioning manoeuvres. J Laryngol Otol 2010; 124: 905-8.

38. Chiou WY, Lee HL, Tsai SC, Yu TH, Lee XX. A single therapy for all subtypes of horizontal canal positional vertigo. Laryngoscope 2005; 115: 1432-5.

39. Jackson LE, Morgan B, Fletcher JC, Krueger WW. Anterior canal benign paroxysmal positional vertigo: an underappreciated entity. Otol Neurotol 2007; 28: 218-22.

40. Nuti D, Agus G, Barbieri MT, Passali D. The management of 
horizontal-canal paroxysmal positional vertigo. Acta Otolaryngo 1998; 118: 445-60.

41. Yacovino DA, Hain TC, Gualtieri F. New therapeutic maneuver for anterior canal benign paroxysmal positional vertigo. J Neurol 2009; 256: 1851-5.

42. Tirelli G, D'Orlando E, Giacomarra V, Russolo M. Benign positional vertigo without detectable nystagmus. Laryngoscope 2001; 111 1053-6.

43. Fife TD. Recognition and management of horizontal canal benign positional vertigo. Am J Otol 1998; 19:345-51.

44. Squires TM, Weidman MS, Hain TC, Stone HA. A mathematical model for top-shelf vertigo: the role of sedimenting otoconia in BPPV. J Biomech 2004; 37: 1137-46.

45. Lin SZ, Fan JP, Sun AH, Guan J, Liu HB, Zhu QB. Efficacy of laser occlusion of posterior semicircular canal for benign paroxysmal positional vertigo: case report. J Laryngol Otol 2010; 124: e5.

46. Rashad UM. Patients with benign paroxysmal positional vertigo and cervical spine problems: is Epley's manoeuvre contraindicated and is a proposed new manoeuvre effective and safer? J Laryngol Otol 2010; 124: 1167-71.

47. Casqueiro JC, Ayala A, Monedero G. No more postural restrictions in posterior canal benign paroxysmal positional vertigo. Otol Neurotol 2008; 29: 706-9.

48. Korres S, Balatsouras DG, Ferekidis E. Prognosis of patients with benign paroxysmal positional vertigo treated with repositioning manoeuvres. J Laryngol Otol 2006; 120: 528-33.

49. Semont A, Freyss G, Vitte E. Curing the BPPV with a liberatory manoeuvre. Adv Otorhinolaryngol 1988; 42: 290-3.

50. Nuti D, Vannucchi P, Pagnini P. Benign paroxysmal vertigo of the horizontal canal: a form of canalolithiasis with variable clinica features. J Vestib Res 1996; 6: 173-84.

51. Yacovino DA, Hain TC, Gualtieri F. New therapeutic maneuver for anterior canal benign paroxysmal positional vertigo. J Neurol 2009,
256: $1851-5$

52. Honrubia V, Baloh RW, Harris MR, Jacobson KM. Paroxysmal positional vertigo syndrome. Am J Otol 1999; 20: 465-70.

53 Rahko T. The test and treatment methods of benign paroxysmal positional vertigo and an addition to the management of vertigo due to the superior vestibular canal (BPPV-SC). Clin Otolaryngol Allied Sci 2002; 27: 392-5.

54. Crevits L. Treatment of anterior canal benign paroxysmal positional vertigo by a prolonged forced position procedure. J Neurol Neurosurg Psychiatry 2004; 75: 779-81

55. Helminski JO, Hain TC. Evaluation and treatment of benign paroxysmal positional vertigo. Ann Long Term Care 2007; 15: 339.

56. Marciano E, Marcelli V. Postural restrictions in labyrintholithiasis. Eur Arch Otorhinolaryngol 2002; 259: 262-5.

57. Moon SJ, Bae SH, Kim HD, Kim JH, Cho YB. The effect of postural restrictions in the treatment of benign paroxysmal positional vertigo. Eur Arch Otorhinolaryngol 2005; 262: 408-11.

58. Cakir BO, Ercan I, Cakir ZA, Turgut S. Efficacy of postural restriction in treating benign paroxysmal positional vertigo. Arch Otolaryngol Head Neck Surg 2006; 132: 501-5.

59. Vannucchi P, Giannoni B, Pagnini P. Treatment of horizontal semicircular canal benign paroxysmal positional vertigo. J Vestib Res 1997; 7: 1-6.

60. McClure JA. Horizontal canal BPV. Am J Otolaryngol 1985; 14: 305.

61. Epley JM. Human experience with canalith repositioning maneuvers. Am N Y Acad Sci 2001; 942: 179-91.

62. Macias JD, Lambert KM, Massingale S, Ellensohn A, Fritz JA. Variables affecting treatment in benign paroxysmal positional vertigo. Laryngoscope 2000; 110: 1921-4.

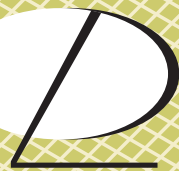 With Best Compliment Life Remedier \\ OMNICA \\ From}

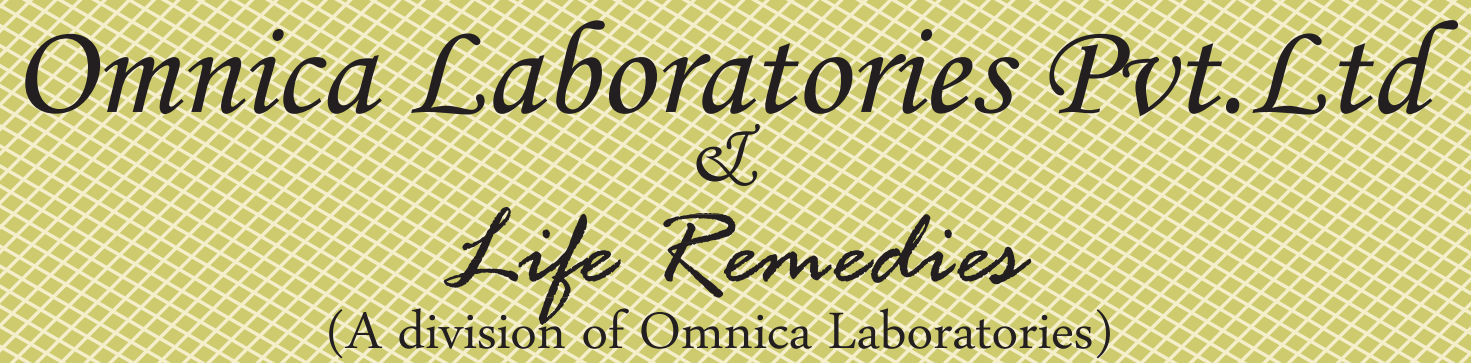

Makers of

$\rightarrow$ ADOZ

(Albendazole lp 400mg Chewable

Chocolate Flavored Tablet)

$\rightarrow$ CORTILONE $5 / 10 / 20 / 40$

(Prednisolone 5/10/20/40/ mg Scored Tablet)

DOXYLENE

(Doxycycline Hyclate $100 \mathrm{mg}$ Capsule)

$\rightarrow$ MIGRID

(Flunarizine $10 \mathrm{mg}$ Tablet)

AZONE 250/500

(Azithromycin 250/500mg Tablet)

$\rightarrow$ MYOLAX $2 / 4$

(Tizanidine2/4mg Tablet)

FLAMOL

(Ibuprofen $1 \mathrm{p} 400 \mathrm{mg}+$ Paracetamo

$325 \mathrm{mg}$ Tablet)MYOLAX 2/4

(Tizanidine $2 / 4 \mathrm{mg}$ Tablet )

CONDOMOL

(Codeine Phosphate $10 \mathrm{mg}$

+Paracetamol $500 \mathrm{mg}$ Tablet)

$\rightarrow$ VERTINORM

(Cinnarizine $25 \mathrm{mg}$ Tablet)

$\rightarrow$ RINZ

(Paracetamol 1. P. $500 \mathrm{mg}$

+Chlorpheniramine Maleate IP $4 \mathrm{mg}$

+Phenyephrine $\mathrm{Hcl}$ IP $10 \mathrm{mg}$ Tablet)
CODOTAB

(Codeine Phosphate $15 \mathrm{mg}$ Tablet)

\section{KOFTAB}

(Bromhexine $8 \mathrm{mg}+$ Phenylephrine

$10 \mathrm{mg}+$ CPA $4 \mathrm{mg}$ Tablet)
KOFTAB - D

(Dextromethorphan HBr Ip $30 \mathrm{mg}$ +Triprolidine HCL IP $5 \mathrm{mg}+$

Phenylephrine HCL IP $10 \mathrm{mg}$ Tablet)

4A, Anil Bhawan. Kamaladi, Kathmandu. GPO Box no 20516 E-mail: omnica@htp.com.np 